\title{
Analysis of Extreme Rainfall Event with Different Microphysics and Parameterization Schemes in WRF Model
}

\author{
Hiren Satishkumar Lekhadiya, Ranjan Kumar Jana \\ Department of Applied Mathematics \& Humanities, Sardar Vallabhbhai National Institute of Technology, Surat, India \\ Email: hslekhadiya3789@gmail.com,rkjana2003@yahoo.com
}

How to cite this paper: Lekhadiya, H.S. and Jana, R.K. (2018) Analysis of Extreme Rainfall Event with Different Microphysics and Parameterization Schemes in WRF Model. Positioning, 9, 1-11. https://doi.org/10.4236/pos.2018.91001

Received: February 1, 2018

Accepted: February 25, 2018

Published: February 28, 2018

Copyright ( $\odot 2018$ by authors and Scientific Research Publishing Inc. This work is licensed under the Creative Commons Attribution International License (CC BY 4.0).

http://creativecommons.org/licenses/by/4.0/

\section{(c) (i) Open Access}

\begin{abstract}
In the present study, the imitation of heavy rainfall event which occurred over Jharkhand during 18 August 2016 was taken as a case study. Weather Research and Forecasting (WRF) model has been utilized for this study. National Centers for Environmental Prediction (NCEP) analysis data is compared with GSMaP data with different combination of physical parameterization scheme like microphysics (MP) and cumulus parameterization (CP). In the present study, three MP schemes: Kessler scheme, Lin et al. scheme and WRF Single-moment 6-class scheme with combination of three CP schemes: Betts-Miller-Janjic scheme, Multi-scale Kain-Fritsch scheme and New simplified Arakawa-Schubert scheme have been used. The model predicted humidity, temperature and precipitation were compared with the GSMaP product. The model nicely depicted the cloud pattern and recognized the rain event spatially. The obtained result shows that the model overestimates the precipitation for all the schemes.
\end{abstract}

\section{Keywords}

Data Assimilation, NWP Model, Prediction, Parameterization Schemes

\section{Introduction}

Numerical Weather Prediction (NWP) models, which include the Weather Research and Forecasting (WRF) model, have gained large attention in climate and weather prediction over the twenty first century. Solving atmospheric governing equations and producing simulation is the main objective of any NWP model

[1]. They've dynamical cores that represent atmospheric techniques and physical schemes that clear up the physics in sub-grid scale method. Resolving sub-grid 
techniques requires parameterization which include the cumulus parameterization schemes [2] [3] and the microphysical schemes [3] [4]. They play an important role in figuring out the vertical structure of moisture and temperature fields of the ecosystem [4]. The use of NWP models in precipitation forecasting is already mounted in lots of operational weather and prediction centers. This will be partially defined with the aid of the demand of progressed precipitation prediction due to the fact that precipitation impacts many financial sectors, including agriculture [5] [6], fisheries [7], transport and different economic activities [8] [9]. Correct precipitation monitoring and prediction is consequently essential for spatial and temporal variability evaluation [9] in addition to weather change studies [10].

Many different parameterization schemes have been developed by various researchers. These schemes have some limitations in predicting of the intensity and track of cyclones. Chang et al. (2009) [11] considered affectability of land surface parameterization on imitation of substantial precipitation occasions with two mesoscale models, in particular MM5 and WRF, recommending that the precipitation prediction is better simulated by WRF as distinguished with MM5 model [12] [13] [14]. Cloud microphysics parameterization schemes desperately impact on forecasted track [15]. Microphysics schemes also considered a key parameter in so many fields like: hydrology, environment and meteorology, because it merges energy fluxes between the surface and the atmosphere [16] [17] [18] [19] [20].

An objective of this study is to evaluate microphysics and cumulus parameterization scheme sensitivity in WRF model over Jharkhand and adjoining region during 0000 UTC 18 August 2016 to 0000 UTC 19 August 2016.

\section{Model Description and Physical Parameterization Scheme Options}

\subsection{Model Description}

The WRF version 3.7.1 and its three dimensional variational (3D-Var) assimilation system were utilized for an extreme rainfall event over Jharkhand. Model is non-hydrostatic, primitive equation and multiple nesting capabilities to enhance resolution over the area of interest. The model which uses horizontal grid is an engaged with Arakawa C-grid staggering and it is fully compressible system of equations. The model domain used in this study has been depicted in Figure 1 with $10 \mathrm{~km}$ spatial resolution and 32 vertical levels over Jharkhand and adjoining region using the boundary condition of NCEP. The detailed configuration of WRF model is given in Table 1.

\subsection{Physical Parameterization Schemes}

The microphysics schemes give the information about the precipitation, cloud and water vapor process. In this study, three different MP schemes have been used to imitate the precipitation event over Jharkhand during 18 August 2016. 


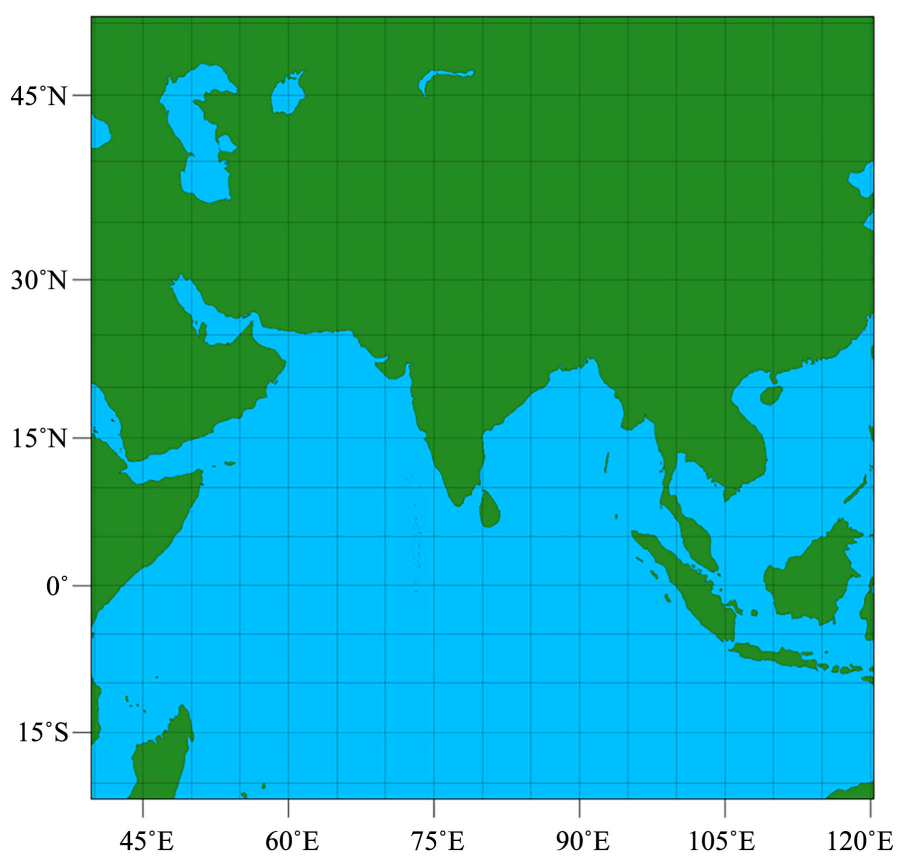

Figure 1. The model domain used in this study.

Table 1. The model configuration used in this study.

\begin{tabular}{ll}
\hline Number of domains & 1 \\
\hline Dynamics & Non-hydrostatic \\
Horizontal grid resolution & $10 \mathrm{~km}$ \\
Integration time step & $90 \mathrm{~s}$ \\
Number of grid points & $300 \times 300$ \\
Horizontal grid distribution & Arakawa C-grid \\
Map projection & Mercator \\
Time integration & $\begin{array}{l}3 \text { rd order Runge-Kutta } \\
\text { Kessler Scheme } \\
\text { Lin et al. Scheme } \\
\text { WRF Single-moment 6-class Scheme }\end{array}$ \\
Cumulus parameterization schemes & $\begin{array}{l}\text { Yonsei University scheme (YSU) } \\
\text { Moisture-advection-based Trigger } \\
\text { Multi-scale Kain-Fritsch Scheme } \\
\text { New Simplified Arakawa-Schubert Scheme }\end{array}$
\end{tabular}

The details of the three MP schemes are given below:

Kessler Scheme: The research displays the character of all likelihood associations among circulations of rain, cloud, water vapor and snow with vertical and horizontal winds, compressibility of the surroundings, divergence of the wind and the energy distribution. The discoveries additionally asset translation of perceptions and they provide instructions to efforts towards synthetic augmentation of precipitation. 
Lin et al. Scheme: It uses two-dimensional, time-based cloud model. It simulates water substance in six distinctive forms: cloud water, water vapor, snow, rain, snow and hail, i.e. graupel. The majority of water microphysical parameterization methods which have been used by the model to symbolize the precipitation fields are all assumed to observe exponential size distribution capabilities.

WRF Single-moment 6-class Scheme: In this scheme revised ice-microphysics is used in addition to the simple (WRF Single-Moment 3-class Microphysics scheme; WSM3) and mixed-phase (WRF Single-Moment 5-class Microphysics scheme; WSM5). The WSM6 was developed for the incorporation of graupel as another predictive variable.

Three MP schemes with combination of three CP schemes have been used to simulate the heavy rainfall event. The details of three CP schemes have been given below:

Betts-Miller-Janjic Scheme: Betts and Miller proposed a convective adjustment scheme that consists of both shallow and deep convection. The deep convection in the Betts-Miller scheme is much like the opposite modification schemes. It makes use of experimentally based quasi-equilibrium thermodynamic profiles as a kind of perspective state in place of a wet adiabatic condition. The fundamental form of those quasi-equilibrium reference profiles is constructed absolutely in light of the various perceptions. The production of the reference profiles and the determination of the unwinding timescale are fundamental additives substances of the Betts-Miller scheme. Perceptions display that quasi equilibria are one of a kind for uncommon convective areas; in this manner, for appropriate production of reference profiles, it is essential to track the alteration parameters for various convective regions.

Multi-scale Kain-Fritsch Scheme: An updated Kain-Fritsch (KF) scheme is based on the study of sub grid-scale, cloud-radiation interactions for improving high-resolution precipitation forecast. In this scheme grid resolution dependency is introduced, the adjustment entrainment process and timescale that influence surface precipitation are modified.

New Simplified Arakawa-Schubert Scheme: The Simplified Arakawa-Schubert scheme parameterizes the impact of deep convection at the surroundings (represented through the model state variables) within the following way. First, an easy cloud model is used to determine the alternate in model state variables because of one entraining/detraining cloud type, according to unit cloud-base mass flux. Subsequently, the entire trade in state variables is retrieved via figuring out the real cloud base mass flux, the usage of the quasi-equilibrium assumption, wherein convection is assumed to be steady-state. This means that the technology of the cloud work feature (interpreted as entrainment-moderated convective available potential energy (CAPE)) by way of the big scale dynamics is in balance with the consumption of the cloud work feature by way of the convection.

A detailed study on the impact of different combinations of MP and CP schemes on rainfall event using WRF-ARW model is carried out. Total 9 expe- 
riments were performed by using three different MP schemes coupling with three CP schemes. The details of the experiments are reported in Table 2.

\section{Case study and Data Used}

\subsection{Case Study}

We have taken an extreme rainfall event which occurred at Jharkhand during 18th August, 2016 as the case study. From GSMaP data $24 \mathrm{~h}$ accumulated rainfall during 0000 UTC 18 July 2016 - 0000 UTC 19 July 2016 is shown in Figure 2. From Figure 2, we can see that there was $110 \mathrm{~mm}$ rainfall in $24 \mathrm{~h}$ at Jharkhand and adjoining region.

Table 2. Description of the numerical experiments with their combinations.

\begin{tabular}{ccc}
\hline Experiment Name & MP scheme & CP scheme \\
a1 & KS & Betts-Miller-Janjic Scheme \\
a2 & KS & Multi-scale Kain-Fritsch Scheme \\
a3 & KS & New Simplified Arakawa-Schubert Scheme \\
b1 & Lin & Betts-Miller-Janjic Scheme \\
b2 & Lin & Multi-scale Kain-Fritsch Scheme \\
c1 & Lin & New Simplified Arakawa-Schubert Scheme \\
c2 & WSM-6 & Betts-Miller-Janjic Scheme \\
c3 & WSM-6 & Multi-scale Kain-Fritsch Scheme \\
\hline
\end{tabular}

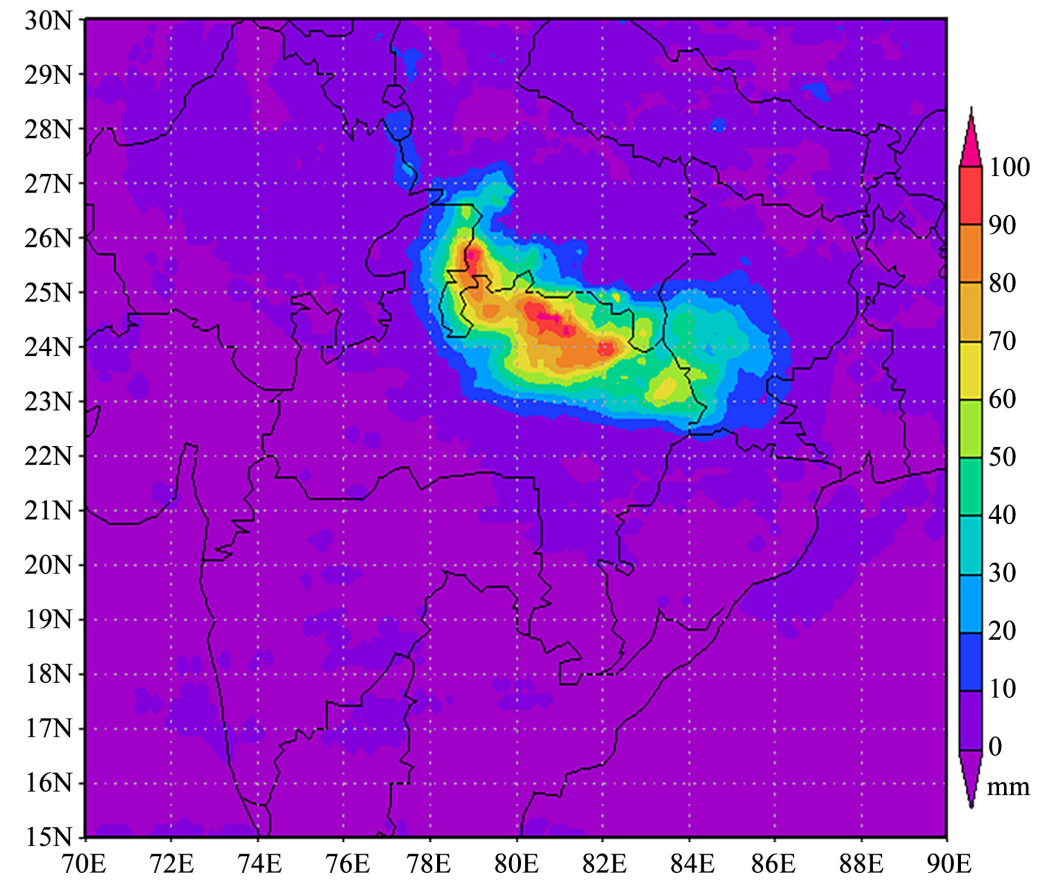

Figure 2. $24 \mathrm{~h}$ accumulated rainfall from GSMaP. 


\subsection{Data Used}

The thermodynamic profiles are retrieved from INSAT-3D data at 43 pressure levels and the retrieved data is available at L2B product from Meteorological \& Oceanographic Satellite Data Archival Centre (MOSDAC) of Indian Space Research Organization (ISRO) (url: http://www.mosdac.gov.in/). For generating the initial and boundary conditions the Global Forecast System (GFS), $0.5^{\circ} \times 0.5^{\circ}$ resolution model forecast data from NCEP have been used. The Global Satellite Mapping of Precipitation (GSMaP) data is supported by Japan Science and Technology Agency (JST) and Japan Aerospace Exploration Agency (JAXA). The GSMaP data is used for the comparison.

\section{Data Assimilation Methodology}

The data assimilation is an improvement strategy for enhancing the initial conditions by combination of the high-resolution perception information and model background information (GFS initial condition) through iterative methods. The 3D-Var assimilation procedure is a calculus-based technique and minimizing the error through minimizing the cost function $J(x)$, characterized in Equation (1). The 3D-Var assimilation procedure is used conjugate gradient strategy for minimizing the objective function. The subtle elements of the 3D-Var assimilation strategies are accessible.

$$
\begin{aligned}
J(x) & =J^{b}+J^{o} \\
& =\left(x-x^{b}\right)^{T} B^{-1}\left(x-x^{b}\right)+\left(y^{o}-H(x)\right)^{T} R^{-1}\left(y^{o}-H(x)\right)
\end{aligned}
$$

where

$$
\begin{aligned}
& J(x)=\text { total error } \\
& J^{b}=\text { error in background } \\
& J^{o}=\text { error in observation } \\
& x=\text { current state } \\
& x^{b}=\text { background state } \\
& y^{o}=\text { observation vector } \\
& B=\text { error covariance matrix of background state } \\
& R=\text { error covariance matrix of observation } \\
& H(x)=\text { observation operator }
\end{aligned}
$$

\section{Experimental Design}

Total ten experiments are performed for the present study, i.e. control (CNT) and experiment (EXP). In EXP there are nine cases already discussed. In both of the experiments initial model forecast has been configure for six hour started from 0018 UTC 17 August 2016 to 0000 UTC 18 August 2016 and take that as first guess (FG). For CNT run only GFS data is assimilated at 0000 UTC $18 \mathrm{Au}-$ gust 2016 to 0000 UTC 19 August 2016, while in EXP run GFS data along with INSAT-3D retrieved temperature and humidity profiles are assimilated. For both the experiments the WRF model has been integrated for $24 \mathrm{~h}$ starting from 
0000 UTC 18 August 2016 to 0000 UTC 19 August 2016. The design of the experiments can find in following Figure 3.

\section{Results and Discussion}

Vertical profile of domain average Root Mean Square Deviation (RMSD) for 24 $\mathrm{h}$ temperature and humidity forecast for $500 \mathrm{hPa}$ are shown in Figure 4 and Figure 5 respectively. Some experiment gives positive impact throughout the domain at $500 \mathrm{hPa}$. While vertical profile of domain average RMSD for $24 \mathrm{~h}$ temperature and humidity forecast for $850 \mathrm{hPa}$ are shown in Figure 6 and Figure 7 respectively. It shows that temperature profile at $850 \mathrm{hPa}$ gives negative improvement throughout the domain and humidity profile at $850 \mathrm{hPa}$ gives positive improvement throughout the domain.

Model simulated precipitation at 0000 UTC 18th August 2016 to 0000 UTC 19th August 2016 using different MP schemes coupling with Betts-Miller-Janjic Scheme, Multi-scale Kain-Fritsch Scheme and New Simplified Arakawa-Schubert Scheme with the initial condition at 1800 UTC 17 August 2016 have been represented pictographically. The Figure 8 suggests that all the experiment overestimates the precipitation. In addition, experiment b2 and c2 match with the actual result taken from GSMaP data. All other results are also fine but b2 and c2 are good results. The Lin et al. and WSM-6 MP scheme with combination of Multi-scale Kain-Fritsch CP scheme gives best results.

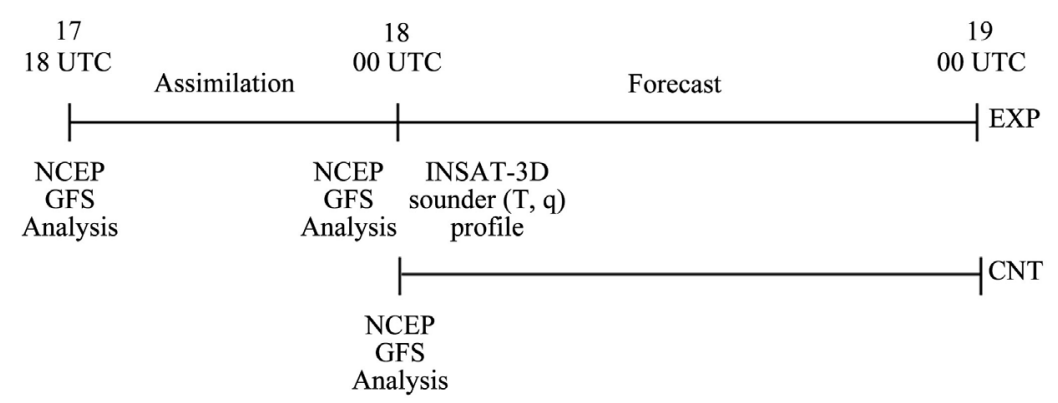

Figure 3. Schematic diagram of the experiment design shows the data assimilation process and forecast.

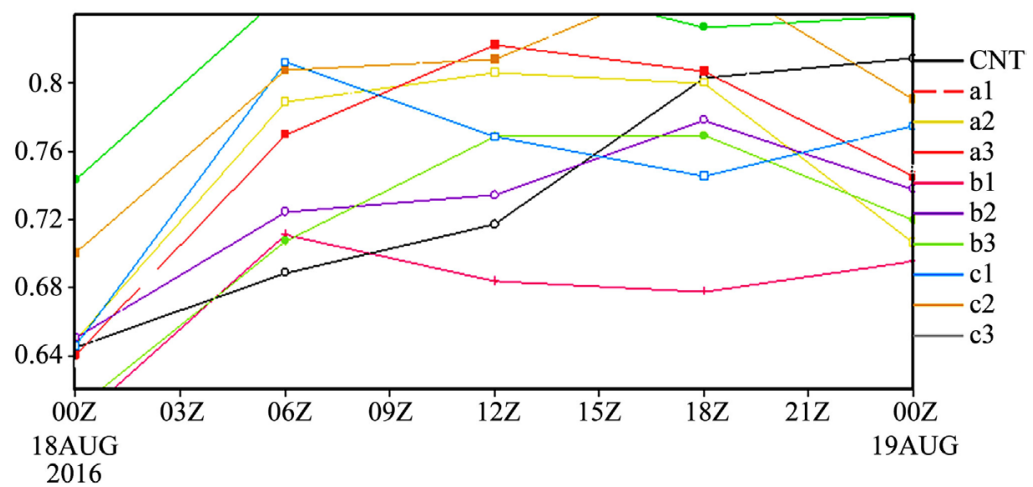

Figure 4. Vertical profile of domain average RMSD of $24 \mathrm{~h}$ temperature forecast from all experiments at $500 \mathrm{hPa}$. 


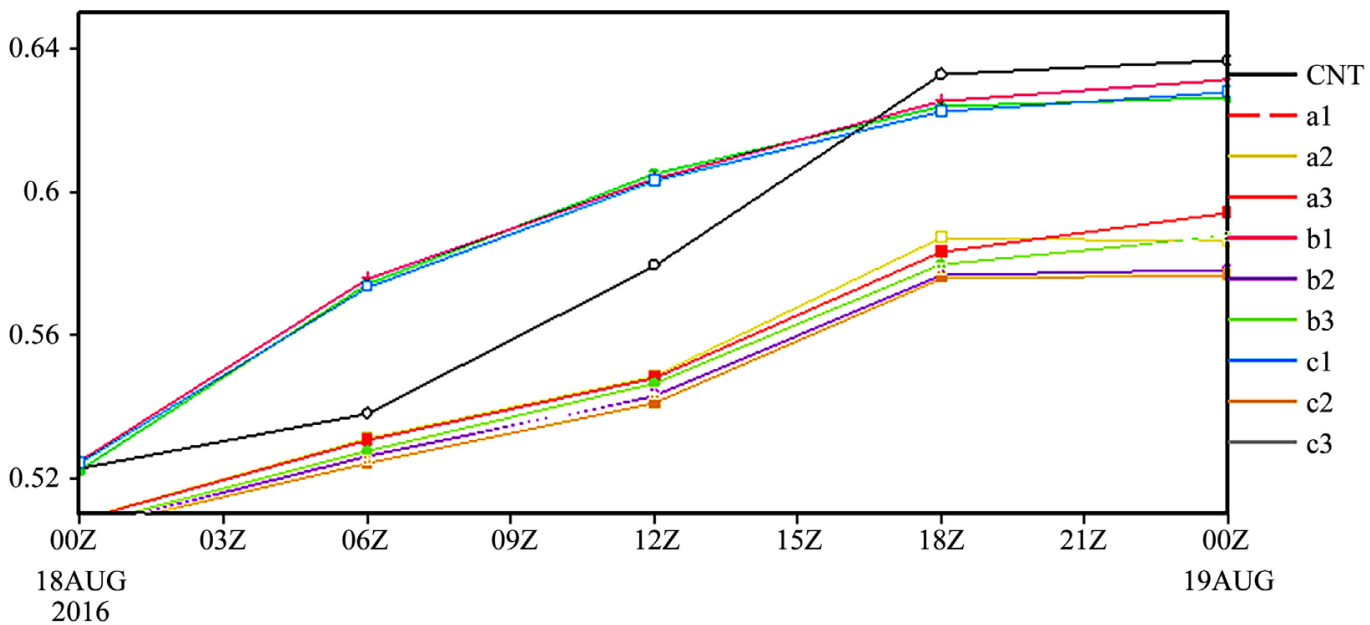

Figure 5. Vertical profile of domain average RMSD of $24 \mathrm{~h}$ humidity forecast from all experiments at $500 \mathrm{hPa}$.

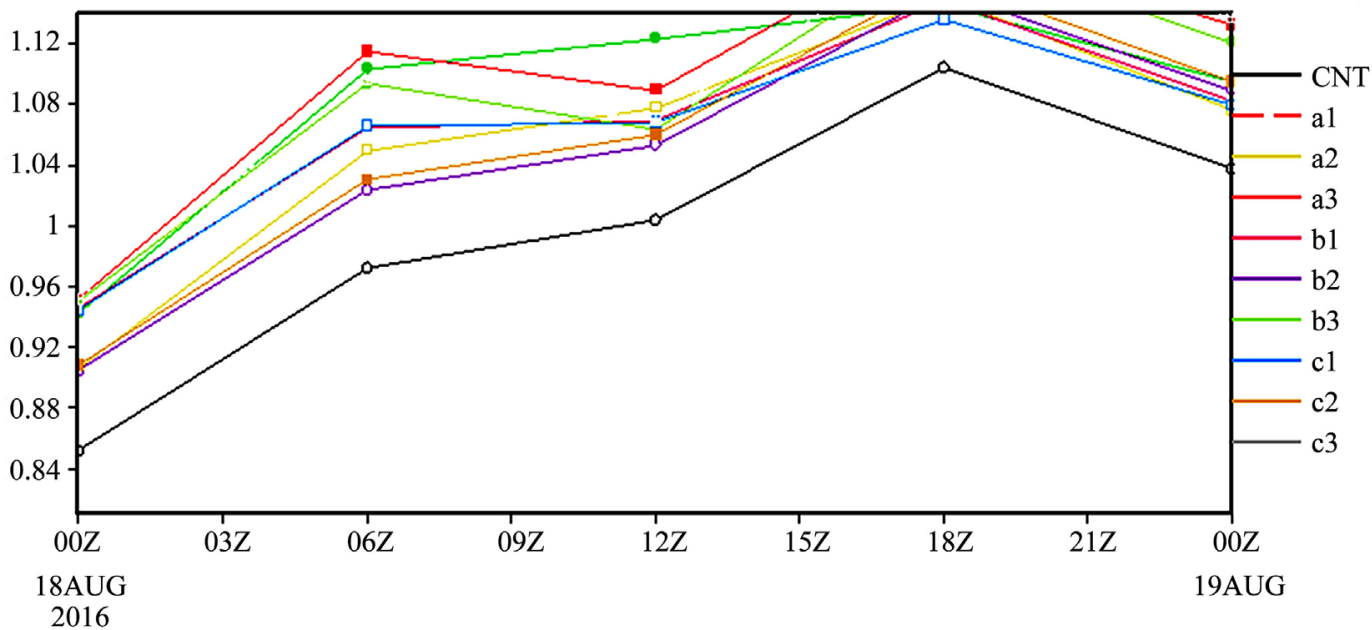

Figure 6. Vertical profile of domain average RMSD of $24 \mathrm{~h}$ temperature forecast from all experiments at $850 \mathrm{hPa}$.

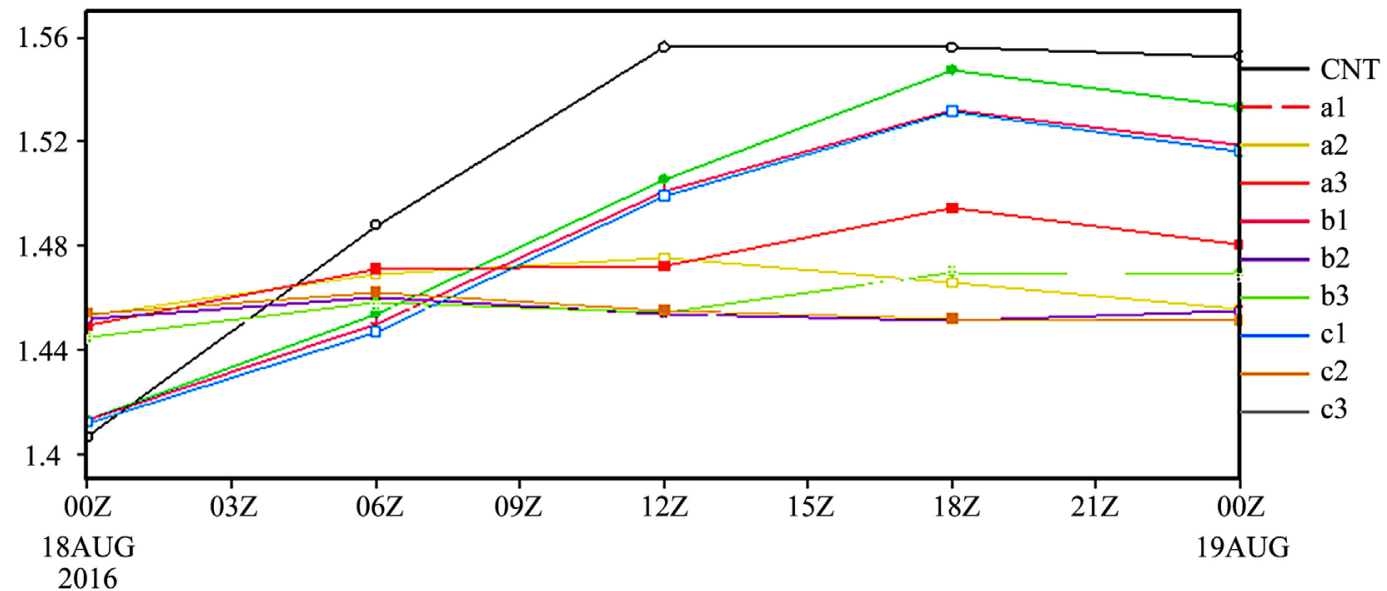

Figure 7. Vertical profile of domain average RMSD of $24 \mathrm{~h}$ humidity forecast from all experiments at 850 $\mathrm{hPa}$. 


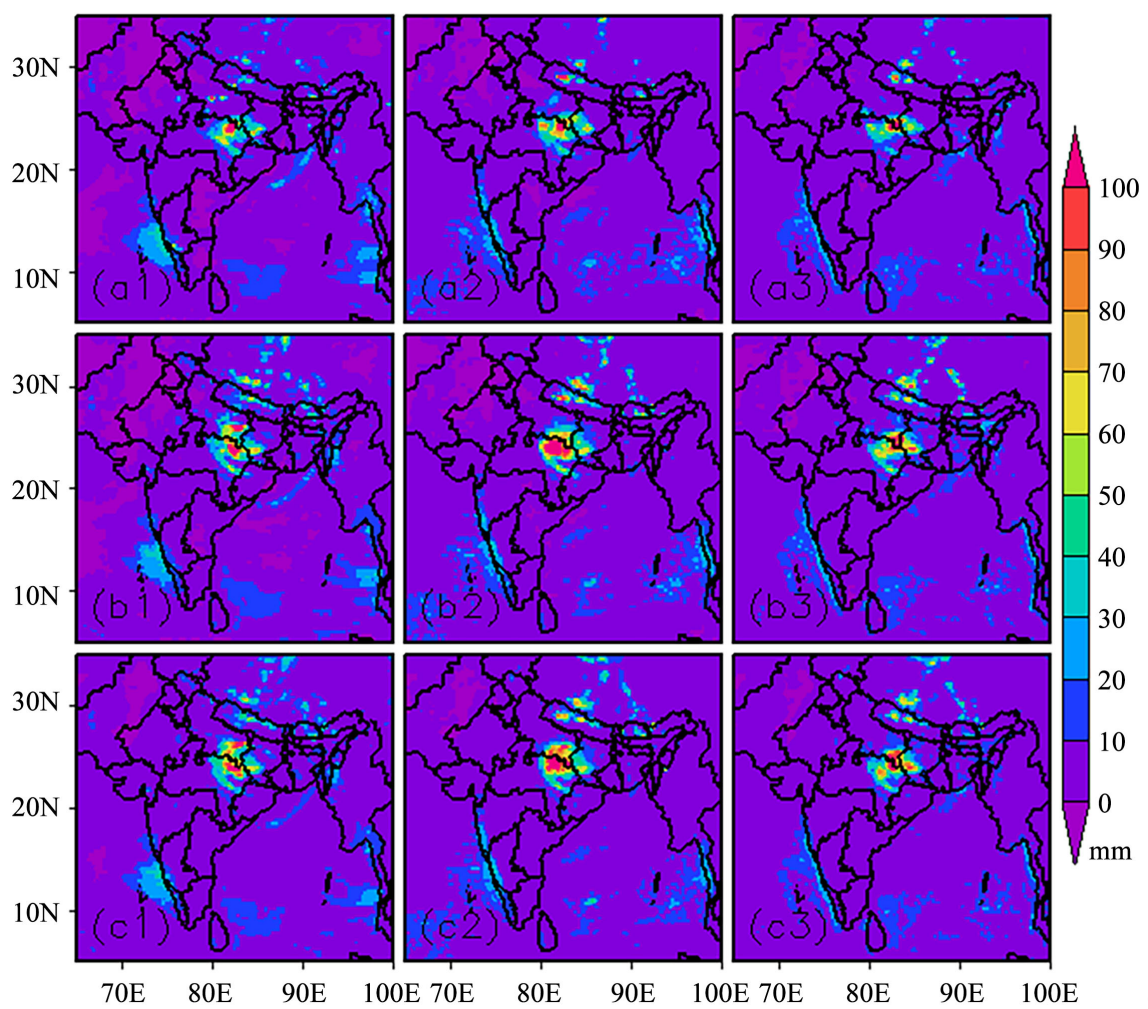

Figure 8. Spatial distribution of improvement parameter in 24 h (0000 UTC 18 August 2016 to 0000 UTC 19 August 2016) precipitation forecast for all experiments.

\section{Conclusion}

The present study utilizes the performance of the different parameterization schemes in WRF model at Jharkhand during 0000 UTC 18 August 2016 - 0000 UTC 19 August 2016. It has been observed from the numerical experiments that the experiment $\mathrm{b} 2$ and $\mathrm{c} 2$ gives best match with actual rainfall. So, we conclude that Lin et al. Scheme and WRF Single-moment 6-class MP scheme with combination of Multi-scale Kain-Fritsch CP scheme give good result for rainfall.

\section{Acknowledgements}

The author acknowledges Mesoscale and Microscale Division of NCAR for WRF-ARW model system. They are also thankful to the National Oceanic and Atmospheric Administration (NOAA) for GFS analysis data and MOSDAC for INSAT-3D sounder data. Both the authors are grateful to SVNIT for financial support for this research work.

\section{References}

[1] Coiffier, J. (2011) Fundamentals of Numerical Weather Prediction. Cambridge University Press, New York. https://doi.org/10.1017/CBO9780511734458

[2] Flaounas, E., Bastin, S. and Janicot, S. (2011) Regional Climate Modelling of the 2006 West African Monsoon: Sensitivity to Convection and Planetary Boundary Layer Parameterization Using WRF. Climate Dynamics, 36, 1083-1105. 
https://doi.org/10.1007/s00382-010-0785-3

[3] Sun, X., Xie, L., Semazzi, F.H. and Liu, B. (2014) A Numerical Investigation of the Precipitation over Lake Victoria Basin Using a Coupled Atmosphere-Lake Limited-Area Model. Advances in Meteorology, 2014, 1-15. https://doi.org/10.1155/2014/960924

[4] Mayor, Y.G. and Mesquita, M.D. (2015) Numerical Simulations of the 1 May 2012 Deep Convection Event over Cuba: Sensitivity to Cumulus and Microphysical Schemes in a High-Resolution Model. Advances in Meteorology, 2015, Article ID: 973151. https://doi.org/10.1155/2015/973151

[5] Mugume, I., Mesquita, M.D., Basalirwa, C., Bamutaze, Y., Reuder, J., Nimusiima, A., Waiswa, D., Mujuni, G., Tao, S. and Ngailo, T.J. (2016) Patterns of Dekadal Rainfall Variation over a Selected Region in Lake Victoria Basin, Uganda. Atmos phere, 7, 150. https://doi.org/10.3390/atmos7110150

[6] Tao, S., Shen, S., Li, Y., Wang, Q., Gao, P. and Mugume, I. (2016) Projected Crop Production under Regional Climate Change Using Scenario Data and Modeling: Sensitivity to Chosen Sowing Date and Cultivar. Sustainability, 8, 214. https://doi.org/10.3390/su8030214

[7] Kizza, M., Rodhe, A., Xu, C.Y., Ntale, H.K. and Halldin, S. (2009) Temporal Rainfall Variability in the Lake Victoria Basin in East Africa during the Twentieth Century. Theoretical and Applied Climatology, 98, 119-135.

https://doi.org/10.1007/s00704-008-0093-6

[8] Bentzien, S. and Friederichs, P. (2012) Generating and Calibrating Probabilistic Quantitative Precipitation Forecasts from the High-Resolution NWP Model COSMO-DE. Weather and Forecasting, 27, 988-1002. https://doi.org/10.1175/WAF-D-11-00101.1

[9] Beskow, S., Caldeira, T.L., de Mello, C.R., Faria, L.C. and Guedes, H.A.S. (2015) Multi Parameter Probability Distributions for Heavy Rainfall Modeling in Extreme Southern Brazil. Journal of Hydrology: Regional Studies, 4, 123-133.

[10] Ngailo, T., Shaban, N., Reuder, J., Rutalebwa, E. and Mugume, I. (2016) Non Homogeneous Poisson Process Modelling of Seasonal Extreme Rainfall Events in Tanzania. International Journal of Science and Research (IJSR), 5, 1858-1868.

[11] Chang, H.I., Kumar, A., Niyogi, D., Mohanty, U., Chen, F. and Dudhia, J. (2009) The Role of Land Surface Processes on the Mesoscale Simulation of the July 26, 2005 Heavy Rain Event over Mumbai, INDIA. Global and Planetary Change, 67, 87-103. https://doi.org/10.1016/j.gloplacha.2008.12.005

[12] Braun, S.A. and Tao, W.K. (2000) Sensitivity of High-Resolution Simulations of Hurricane Bob (1991) to Planetary Boundary Layer Parameterizations. Monthly Weather Review, 128, 3941-3961. https://doi.org/10.1175/1520-0493(2000)129\%3C3941:SOHRSO\%3E2.0.CO;2

[13] Mandal, M., Mohanty, U. and Raman, S. (2004) A Study on the Impact of Parameterization of Physical Processes on Prediction of Tropical Cyclones over the Bay of Bengal with NCAR/PSU Mesoscale Model. Natural Hazards, 31, 391-414. https://doi.org/10.1023/B:NHAZ.0000023359.24526.24

[14] Rao, D.B. and Prasad, D.H. (2007) Sensitivity of Tropical Cyclone Intensification to Boundary Layer and Convective Processes. Natural Hazards, 41, 429-445. https://doi.org/10.1007/s11069-006-9052-7

[15] Fovell, R.G. and Su, H. (2007) Impact of Cloud Microphysics on Hurricane Track Forecasts. Geophysical Research Letters, 34. https://doi.org/10.1029/2007GL031723

[16] Anderson, M., Norman, J., Diak, G., Kustas, W. and Mecikalski, J. (1997) A 
Two-Source Time Integrated Model for Estimating Surface Fluxes Using Thermal Infrared Remote Sensing. Remote Sensing of Environment, 60, 195-216. https://doi.org/10.1016/S0034-4257(96)00215-5

[17] Anderson, M.C., Hain, C., Wardlow, B., Pimstein, A., Mecikalski, J.R. and Kustas, W.P. (2011) Evaluation of Drought Indices Based on Thermal Remote Sensing of Evapotranspiration over the Continental United States. Journal of Climate, 24, 2025-2044. https://doi.org/10.1175/2010JCLI3812.1

http://journals.ametsoc.org/doi/abs/10.1175/2010JCLI3812.1

[18] Wan, Z. and Dozier, J. (1996) A Generalized Split-Window Algorithm for Retrieving Land Surface Temperature from Space. IEEE Transactions on Geoscience and Remote Sensing, 34, 892-905. https://doi.org/10.1109/36.508406

[19] Weng, Q., Lu, D. and Schubring, J. (2004) Estimation of Land Surface Temperature Vegetation Abundance Relationship for Urban Heat Island Studies. Remote Sensing of Environment, 89, 467-483. https://doi.org/10.1016/j.rse.2003.11.005

[20] Zhou, L., Dickinson, R., Tian, Y., Zeng, X., Dai, Y., Yang, Z.L., Schaaf, C., Gao, F., Jin, Y., Strahler, A., Myneni, R.B., Yu, H., Wu, W. and Shaikh, M. (2003) Comparison of Seasonal and Spatial Variations of Albedos from Moderate-Resolution Imaging Spectroradiometer (MODIS) and Common Land Model. Journal of Geophysical Research: Atmospheres, 108, 1-20. 